\title{
Plasmonic luminescent down shifting layers for the enhancement of CdTe mini-modules performance
}

\author{
Hind Ahmed \\ Trinity College Dublin, Ireland, hahmed@tcd.ie \\ S.J. McCormack \\ Trinity College Dublin, Ireland \\ John Doran \\ Technological University Dublin, john.doran@tudublin.ie
}

Follow this and additional works at: https://arrow.tudublin.ie/dubenart

Part of the Oil, Gas, and Energy Commons, and the Physics Commons

\section{Recommended Citation}

H. Ahmed, S.J. McCormack, J. Doran, Plasmonic luminescent down shifting layers for the enhancement of CdTe mini-modules performance, Solar Energy, Volume 141, 2017, Pages 242-248, ISSN 0038-092X, DOI: 10.1016/j.solener.2016.11.036.

This Article is brought to you for free and open access by the Dublin Energy Lab at ARROW@TU Dublin. It has been accepted for inclusion in Articles by an authorized administrator of ARROW@TU Dublin. For more information, please contact arrow.admin@tudublin.ie, aisling.coyne@tudublin.ie,gerard.connolly@tudublin.ie.

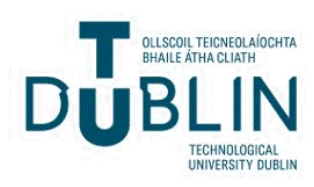




\title{
Plasmonic luminescent down shifting layers for the enhancement of CdTe mini-modules performance
}

\author{
H. Ahmed ${ }^{\mathrm{a}, *}$, S.J. McCormack ${ }^{\mathrm{a}}$, J. Doran ${ }^{\mathrm{b}}$ \\ a School of Engineering, Trinity College Dublin, Dublin, Ireland \\ ${ }^{\mathrm{b}}$ Dublin Energy Lab, Dublin Institute of Technology, Dublin, Ireland
}

\section{A R T I C L E I N F O}

\section{Article history:}

Received 29 July 2016

Received in revised form 17 November 2016

Accepted 21 November 2016

Available online 9 December 2016

\section{Keywords:}

Spectral losses

Luminescent down-shifting (LDS)

Lumogen yellow

Plasmonic

Silver nanoparticles (Ag NPs)

Plasmonic Luminescent Down-Shifting

(pLDS) layers

Surface plasmon resonance (SPR)

Photovoltaics

CdTe mini modules

\begin{abstract}
A B S T R A C T
In this investigation, plasmonic coupling between luminescent species (lumogen yellow, and silver nanoparticles (Ag NPs) has been exploited to produce significant enhancement in absorption and fluorescence emission of lumogen yellow dye luminescent downshifting (LDS) layers. The optimum dye concentration in a poly(methyl,methacrylate) polymer LDS layer of $\sim 100 \mu \mathrm{m}$ thickness was established. Subsequently, plasmonic coupling with Ag NPs was introduced and optimum concentration has been determined for the composite plasmonic Luminescent Down-Shifting (pLDS) layers. The optimum plasmonic coupling has been observed to produce fluorescence emission enhancement of up to $81 \%$ for the dye-pLDS layers. The pLDS layers were deposited on top of CdTe mini-modules to investigate the action of plasmonic interaction in LDS layers. It has been demonstrated that the addition of pLDS layers containing lumogen yellow dye increases the short circuit current density $\left(\mathrm{J}_{\mathrm{sc}}\right)$ of $\mathrm{CdTe}$ devices between 300 and $500 \mathrm{~nm}$. An increase of $\sim 100 \%$ has been achieved. External quantum efficiency (EQE) measurements of the pLDS layers have also shown significant improvement below $500 \mathrm{~nm}$ reaching $25-40 \%$, while increased efficiency was confirmed with current-voltage $(\mathrm{J}-\mathrm{V})$ measurements.
\end{abstract}

(c) 2016 Elsevier Ltd. All rights reserved.

\section{Introduction}

Harvesting solar energy has the potential to reduce carbon emissions and to provide clean energy to contribute to sustainable development. Most of the photovoltaic (PV) research to date has focused on achieving higher PV conversion efficiency at lower cost. In order for high efficiencies to be achieved in PV technologies, energy loss mechanisms must be reduced. One principle energy loss in the conversion of solar energy to electricity is related to spectral losses, whereby low energy photons are not absorbed by the solar cell while high energy photons are not used efficiently. There is potential to increase PV device efficiency by making better use of short wavelength light. Luminescent down-shifting (LDS) is an optical approach to increase a solar cell's spectral response by using luminescent materials to convert high short wavelength photons (300-500 nm) to longer wavelength where solar cell efficiency is higher (Van Sark et al., 2005; Klampaftis et al., 2009, 2012; Ross et al., 2012, 2014; Ahmed et al., 2013, 2016a;

\footnotetext{
* Corresponding author.

E-mail address: hahmed@tcd.ie (H. Ahmed).
}

Kennedy et al., 2015; Chander et al., 2015; Bella et al., 2015; Griffini et al., 2015; Di Lorenzo et al., 2016). A typical LDS device consists of luminescent species (organic dyes/quantum dots/rare earth materials) doped in a transparent polymer sheet applied on top of the PV cell (McIntosh et al., 2009; Rothemund et al., 2011; Ahmed et al., 2012a, 2012b; Kennedy et al., 2015; Ahmed et al., 2016a). The first research using LDS layers "on top of" PV cells was by Hovel et al. (1979). However, the concept of LDS appears frequently in the literature in the late 1970s, when LDS was utilized for an optical concentration process in so-called luminescent solar concentrators (LSC) (Weber and Lambe, 1976; Goetzberger and Greubel, 1977; Levitt and Weber, 1977; Gallagher et al., 2007; Kennedy et al., 2009; Meredith et al., 2009; Chandra et al., 2015).

Plasmonic Luminescent Down-Shifting (pLDS) is a new optical approach to increase the PV device efficiency by using plasmonic coupling between luminescent materials and metal nanoparticles (MNP) (Ahmed, 2015; Ahmed et al., 2016b). The optical properties of fluorescent species can exhibit dramatic spectral changes in the presence of metal nanoparticles (Reisfeld et al., 1988; Stranik et al., 2005; Noguez, 2006; Ghosh and Pal, 2007; Stranik, 2007; Fort and Gŕesillon, 2008; Catchpole and Polman, 2008; Chandra et al., 2010 , 
2012; Reisfeld, 2010; Ahmed et al., 2016b). In previous work quantum dot pLDS layers have been demonstrated to improve the short circuit current density of c-Si and DSSC devices, reaching up to $\sim 22 \%$ in the region $300-500 \mathrm{~nm}$, demonstrating the possible improvement due to the action of plasmonic interaction (Ahmed et al., 2016b). In this paper pLDS layers of lumogen yellow dye will be investigated for CdTe mini-module solar cells and the results of which are new and original.

\subsection{Plasmonic interaction}

When light interacts with the surface plasmon resonance (SPR) at the surface of metals such as silver it can result in a surface plasmon polariton. In this state the electric field associated with the light is highly amplified in a small evanescent region near the surface of the metal nanoparticles (MNPs) (Stranik et al., 2005; Ghosh and Pal, 2007; Fort and Gŕesillon, 2008; Ahmed et al., 2016b). When a fluorescent species is placed in the range of enhanced local electromagnetic filed (EM) field, plasmonic interaction takes place, which can enhance the light absorption and fluorescent emission rates (Stranik et al., 2005; Fort and Gŕesillon, 2008; Chandra et al., 2010, 2012; Ahmed, 2015; Ahmed et al., 2016b).

There are two enhancements due to the presence of MNPs: (i) an increase of the excitation rate and (ii) an increase in the luminescent quantum yield (LQY). Both are a function of the plasmonic resonance of MNPs. The enhancement is maximized for excitation if the SPR resonance overlaps with the excitation peak wavelength of the luminescent material while the enhancement is maximized for LQY if the SPR resonance overlaps with the peak emission wavelength (Ghosh and Pal, 2007; Stranik, 2007; Fort and Gresillon, 2008). The focus of this study is to investigate the enhancement due to the increase in the excitation rate.

The average excitation rate of the fluorophore molecule is directly proportional to the EM filed intensity and given as (Fort and Gíesillon, 2008);

$\Gamma_{\text {exc }} \propto \varepsilon(\lambda)\left|\hat{p}_{\text {exc }} \cdot E_{1}\right|^{2}$

where $\varepsilon(\lambda)$ is the molecular absorptivity of the fluorophore molecule, $\hat{p}_{\text {exc }}$ is the transition dipole moment and $E_{1}$ is the incident plus the surface plasmon enhanced EM field. The enhanced electric field vector decays exponentially away from the surface of MNPs (Lakowicz et al., 2002; Stranik et al., 2005; Chandra, 2013), and therefore in order to modify the luminescent material absorption and excitation rate it is important to place the fluorescent species in this enhancement region.

There is an optimum spacing before the plasmonic affect can take place. If the distance between the luminescent particle and MNPs is too small then non-radiative transfer of the excitation to the metal becomes likely and the emission is quenched (Lakowicz et al., 2002, 2004; Stranik, 2007; Chandra et al., 2012). If the luminescent species is placed beyond this quenching zone, the fluorescence enhancement should reach a maximum and then decrease as the distance increases (Stranik, 2007). In general plasmonic interaction can be controlled (Chandra et al., 2010; Chandra, 2013) by orientation of the luminescent species with respect to the MNPs surface, the surface plasmon resonance wavelength of MNPs, the spacing between MNPs and luminescent species and/or the spectral overlap of the SPR with the absorption and emission bands of the luminescent species. In this work, plasmonic interaction is controlled by the spectral overlap of the SPR with the absorption of the luminescent species and by the spacing between the luminescent material and the MNPs. The spacing is manipulated by controlling the concentrations of both luminescent species and the MNPs.

\section{Materials and method}

\subsection{Materials}

The luminescent material used in this investigation was organic dye lumogen yellow developed and manufactured by BASF, Germany. A clear polymer poly(methyl methacrylate) (PMMA) (Carl Roth $\mathrm{GmbH}+\mathrm{Co} . \mathrm{KG}$ ) was used for the encapsulation of LDS layers. The MNPs used for the plasmonic interaction was silver (Ag) supplied by Sigma Aldrich. It was chosen because the SPR of the Ag particles is in the UV region (at $399 \mathrm{~nm}$ ) which can be tuned in the synthesis process to match the absorption peaks of lumogen yellow dye. The preparation of the Ag NPs followed the method reported by Ledwith et al. (2007) which produces highly stable shaped particles. Ag NPs of triangular and spherical shapes, with triangular shapes being dominant, were produced. The particles were quite uniform in size distribution with an average diameter of $45 \pm 5 \mathrm{~nm}$. SEM analysis of the Ag NPs has been reported in our previous study (Ahmed et al., 2016b). Dimethylformamide (DMF) solvent (density $0.944 \mathrm{~g} / \mathrm{ml}$ at $20^{\circ} \mathrm{C}$, refractive index 1.43 ) purchased from Sigma Aldrich was used as common solvent for both Ag NPs and lumogen yellow dye.

\section{2. pLDS layers and devices fabrication}

\subsubsection{Optimisation of lumogen yellow dye concentration}

The required quantity of the dye was dispersed in DMF solution, and subsequently sonicated for $15 \mathrm{~min}$ in an ultrasonic bath. Dye/ DMF solution was added to PMMA solution (50 wt\%) magnetically stirred for further $20 \mathrm{~min}$. A homogeneous solution with a range of different concentrations $(0.05,0.15,0.30,0.60,0.90,1.10$ and $1.30 \mathrm{wt} \%$ ) were prepared, drop casted on glass substrates (size $15 \mathrm{~cm} \times 15 \mathrm{~cm} \times 1 \mathrm{~cm})$ and left in an oven (800 mbar at a temperature of $25^{\circ} \mathrm{C}$ ) for $72 \mathrm{~h}$ to cure. Layers were removed from the glass substrate after the curing process by making a small cut at one of the edges and slowly lifting up the layers. Uniform layers were obtained when removed from the glass substrate. The average thickness of the layers was measured by a white light interferometer technique and found to be $0.95 \pm 0.05 \mu \mathrm{m}$.

\subsubsection{Optimisation of $p L D S$ composite layers}

The optimum concentration of the dye was mixed with the $\mathrm{Ag}$ NPs/DMF solution and sonicated in an ultrasonic bath for $25 \mathrm{~min}$, added to the PMMA solution, and magnetically stirred for further $20 \mathrm{~min}$ and then placed in an ultra-sonic bath for another $15 \mathrm{~min}$. A homogeneous solution with different Ag NP concentrations (varied from 0 to $40 \mathrm{ppm}$; $0 \mathrm{ppm}$ refers to sample containing only dye) were prepared. The same process as in Section 2.2.1 was undertaken for the composite layers fabrication. Varying the concentration of the Ag NPs allowed the optimization of the maximum fluorescence enhancement of the dye composite layers.

\subsection{3. $p L D S$ devices fabrication}

The CdTe mini-modules $(15 \mathrm{~cm} \times 15 \mathrm{~cm})$ were purchased from Advanced Solar Power INC, China. The modules were have an active area of $196 \mathrm{~cm}^{2}$ after masking. Devices were fabricated by directly depositing the LDS layers on top of the CdTe minimodules surface, using PMMA solution to glue the layers. The deposited layers were left for three days to dry and stick to the cells as presented in Fig. 1. In order to determine the performance of the CdTe modules before and after downshifting layer encapsulation, the electrical characterization of a reference CdTe solar cell (shown in Fig. 1a) was compared with a CdTe solar cell encapsulated with dye-LDS layer (Fig. 1b), and with pLDS composite layer (Fig. 1c). A few bubbles were observed in the fabricated devices 


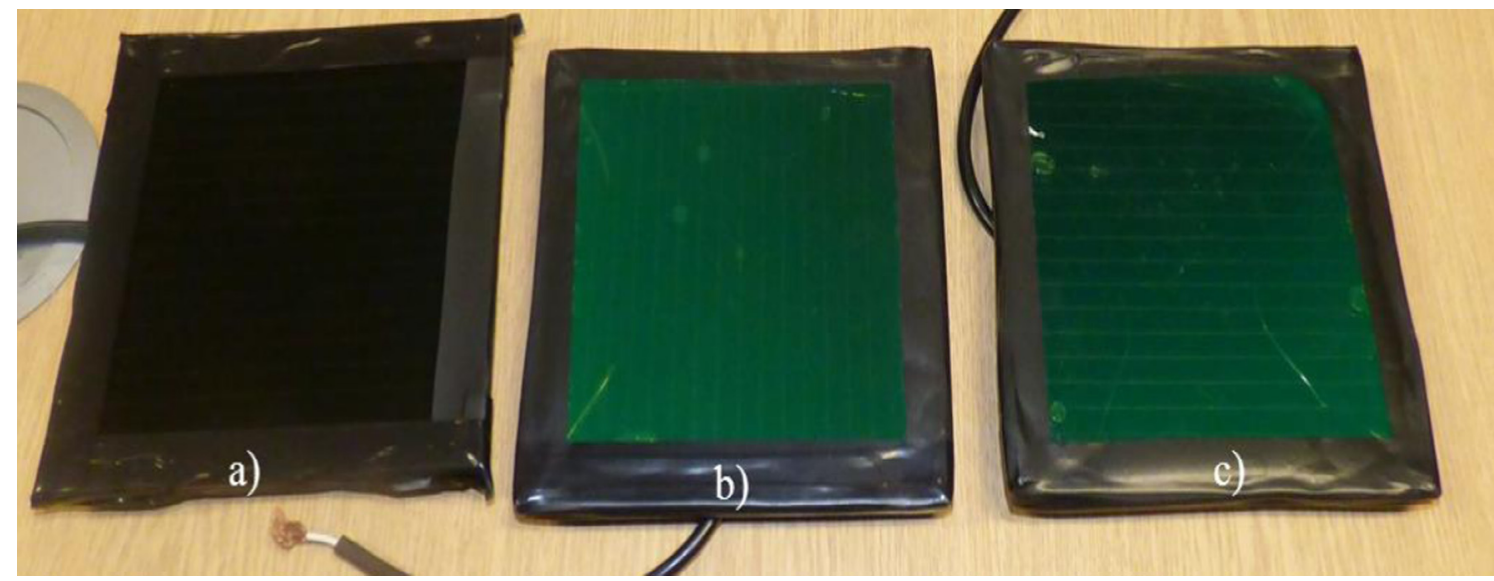

Fig. 1. CdTe mini modules $\left(196 \mathrm{~cm}^{2}\right)$. (a) A clear module, (b) encapsulated with dye-LDS layer and (c) with dye-pLDS composite layer.

which indicated an air gap between the LDS layer and the CdTe mini-modules.

\subsection{Characterisation techniques}

\subsubsection{Spectroscopic characterization}

UV/Vis/NIR absorption spectroscopy was used to measure the absorption characteristics of the down-shifting layers. The UV/ Vis/NIR absorption spectrometer used was a Perkin Elmer Lambda 900 using an integrating sphere configuration to minimize the effect of scattering losses due to the presence of Ag NPs. A blank PMMA sample was used as a reference during the measurements. The emission spectra of the LDS layers were measured by optically pumping samples using a monochromated light source using Luminescence spectrometer Perkin Elmer LS55B.

\subsubsection{I-V measurements}

Current-Voltage measurements were performed with a Keithley 2400 SMU (Source Meter Unit). The light source used was a metal halide discharge lamp (Griven, GR0262). An additional low intensity UV lamp $\left(0.49 \mathrm{~mW} / \mathrm{cm}^{2}\right)$, is introduced so that spectral mismatch is minimized in the region $300-400 \mathrm{~nm}$ where the LDS material absorption is most significant. With this arrangement a solar simulator set-up of class B was achieved. The percentage of spectral irradiance within six defined wavelength bands (300$1100 \mathrm{~nm}$ ) according to the ASTMG173-03 standard and corresponding\% values for the Griven light source with and without an additional UV lamp was reported in our previous paper (Ahmed et al., 2016b). Five current-voltage measurements were taken for each device and results were averaged. The deviation between measurements was less than $3 \%$.

\subsubsection{External quantum efficiency (EQE) measurement}

The EQE system used was Bentham PVE300 of one sun $(1000 \mathrm{~W} /$ $\mathrm{m}^{2}$ ) during the measurements. The system uses a monochromatic probe source from a TMc $300,300 \mathrm{~mm}$ focal length monochromator, and a dual Xenon/quartz halogen light source providing optimum illumination from 300 to $1100 \mathrm{~nm}$ with uncertainties of $5 \%$. The monochromatic beam area is $1.85 \mathrm{~mm}^{2}$ and is directed at the centre of the cell, measuring the photocurrent generated by the cell at each wavelength.

\section{Results and discussion}

Fig. 2 shows the measured absorbance spectra for lumogen yellow dye LDS layer of different concentrations. It has been observed

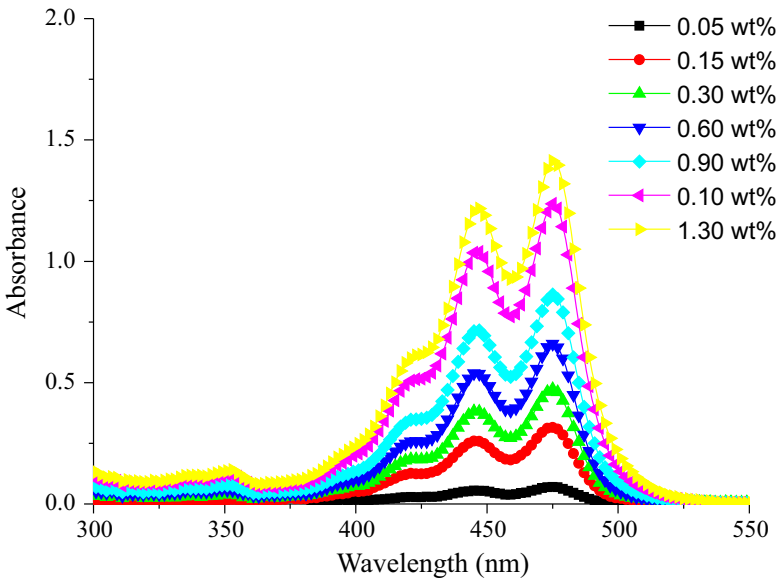

Fig. 2. Absorbance spectra for lumogen yellow day LDS layers of different concentrations.

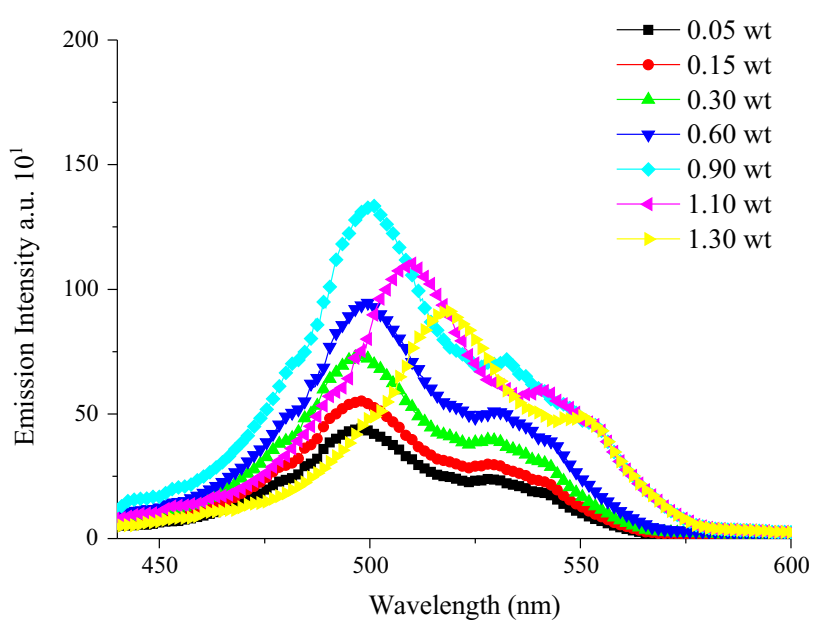

Fig. 3. Emission spectra for lumogen yellow dye LDS layers of different concentrations.

that the peak absorbance intensity increased from 0.06 for lower concentration (0.05 wt\%) to 1.4 for higher concentration (1.30 wt\%). 
Fig. 3 displays the emission spectra measured for lumogen yellow dye LDS layers using emission scan mode at excitation wavelength of $380 \mathrm{~nm}$. It is has been observed that the emission reached its maximum at a concentration of $0.9 \mathrm{wt} \%$ and then decreased for higher concentrations. It is seen from emission measurements that the spectra are slightly red-shifted with increasing the dye concentration. However significant red-sift occurs after concentration of $0.9 \mathrm{wt} \%$ onwards due to so-called inner filter or self-absorption effects. The inner filter effects are results of two processes, first: absorption of the excitation light: this occurs when using a high concentration of the absorbing molecules, where a significant fraction of incident light is absorbed very close to the front wall of the cuvette. As a result, emitted light may not be visible to the detector. Second: absorption of the emitted light: reabsorption occurs at higher concentrations as emitted photons are absorbed by another molecule before reaching the detector. In both cases, the inner filter effects change the spectrum and intensity of the emitted light.

The integrated absorbance and integrated emission for the LDS layers with their different dye concentrations is shown in Fig. 4. From fluorescent spectroscopy measurements, $0.9 \mathrm{wt} \%$ is the optimum concentrations for lumogen yellow dye. Higher than these concentrations the emission intensity starts to decrease. This optimum concentrations was used when incorporating with the silver nanoparticles in the composite layers fabrication.

Fig. 5 shows absorbance measurements of the different pLDS composite layers prepared with plasmonic coupling of Ag NPs and lumogen yellow dye. The Ag NPs have retained their optical properties during re-dispersion in PMMA and in the curing process. The extinction spectra of Ag NPs in DMF solvent and in PMMA layers was reported in our previous study (Ahmed et al., 2016b).

It was observed that the absorption increased with increasing $\mathrm{Ag}$ NPs concentration (up to $90 \%$ relative increase). The enhancement was calculated as the difference between the absorption spectrum with and without Ag NPs. This enhancement was found to be strongly dependent on the spectral overlap between the luminescent materials absorption peak and the Ag NPs extinction peak (Ahmed, 2015; Ahmed et al., 2016b); a greater overlap leads to higher absorption (Stranik, 2007; Ahmed et al., 2016b).

The observed enhancement of the absorbance can be attributed to the presence of the Ag NPs which enhanced the local photon mode density in the vicinity of the fluorescent particle (Reisfeld, 2010; Ahmed et al., 2016b).
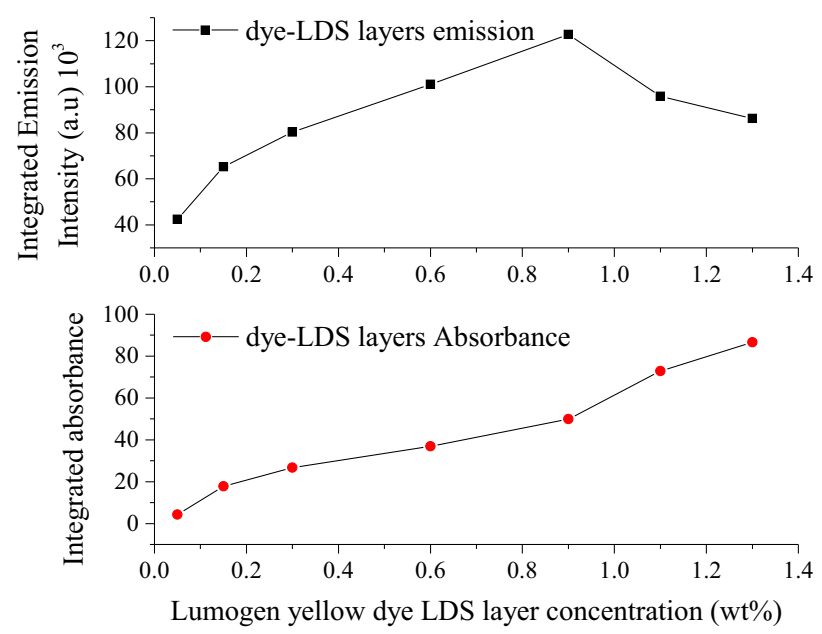

Fig. 4. Integrated absorbance and emission spectra for lumogen yellow dye LDS layers of various concentrations in PMMA.

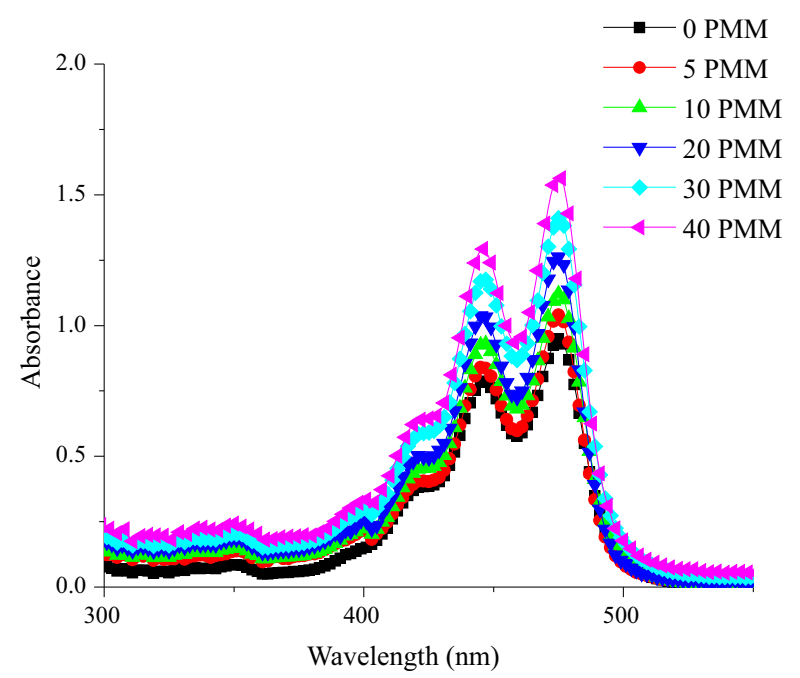

Fig. 5. Absorbance measurements of lumogen yellow dye LDS layers with various Ag NPs concentrations ranging from 0 to $40 \mathrm{ppm}$.

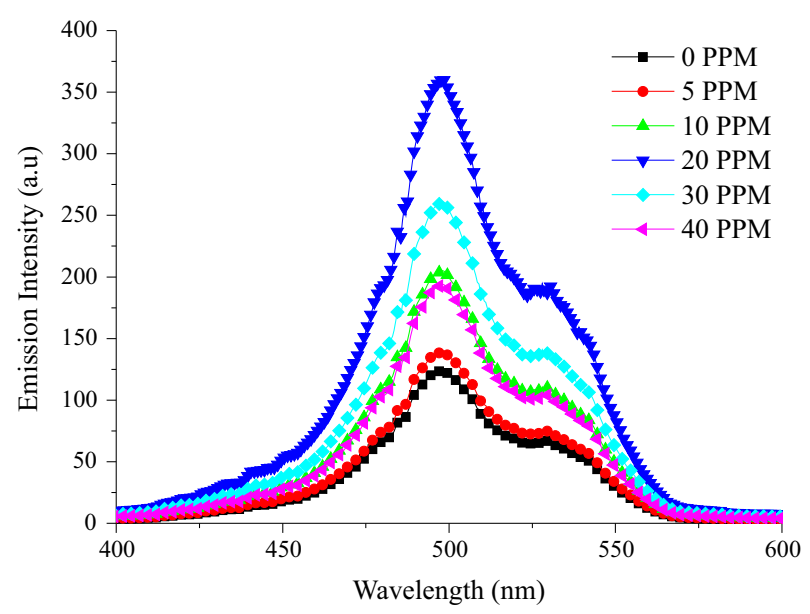

Fig. 6. Emission spectra of lumogen yellow dye with varying Ag NPs concentrations (0-40 ppm) in PMMA composite layer.

Fig. 6 shows the emission measurements of the pLDS composite layers where the excitation wavelength was at $380 \mathrm{~nm}$. The enhancement was calculated as the difference between the emission spectrum with and without Ag NPs. It can be seen from Fig. 6 that the emission increased with increasing Ag NPs concentration, reaching a maximum at concentration of $20 \mathrm{ppm}$, and decreased at higher MNPs concentration.

The measured emission enhancement vs the change in absorbance and Ag NPs concentration for pLDS composite layers is summarized in Fig. 7. The maximum emission enhancement for the pLDS composite layer was found to be $81 \%$ relative to the blank dye-LDS layer. The optimum concentration for Ag NPs was found to be at $20 \mathrm{ppm}$.

Fig. 8 shows the J-V curves for CdTe mini modules-under GR062 illumination for dye-LDS and for the pLDS layers. The increase in the current generation for the plasmonic layer is clearly visible compared to LDS layer containing only dye, and the CdTe bare cell. $\mathrm{J}-\mathrm{V}$ characteristics for CdTe mini-modules with and without Ag NPs incorporation in LDS layers are presented in Table 1.

The electrical characterization showed an increase of $6.1 \%$ in the current density due to the presence of the dye when compared to the bare CdTe mini module. An enhancement of $11.3 \%$ was calcu- 


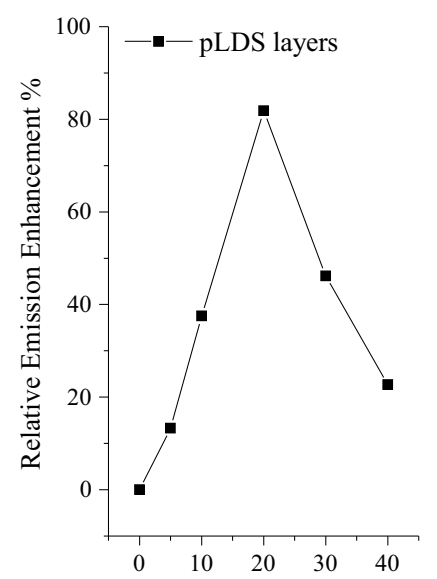

Ag NPs concentration (PPM)

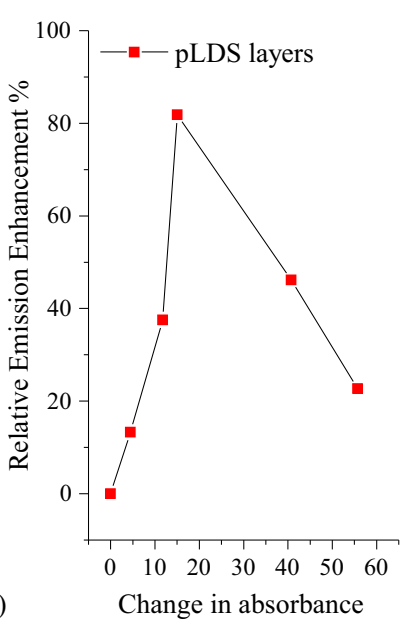

Fig. 7. Relative enhancement vs absorbance (top), and Ag NPs concentration (bottom).

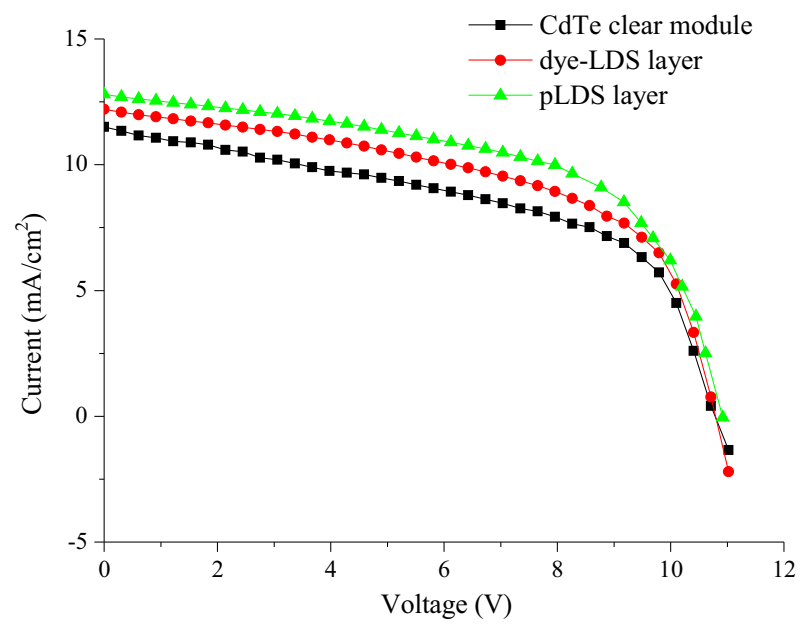

Fig. 8. JV curves of CdTe mini modules with no (i) LDS layer, (ii) with dye-LDS layer and (iii) with dye-pLDS composite layer.

lated for the pLDS composite layer. The differences observed in the current density for the composite layer can be explained by the enhancement due to the presence of the Ag NPs in the pLDS layer (Ahmed et al., 2016b).

The measured EQE of the different configurations are shown in Fig. 9. The EQE of the CdTe mini-modules devices shows an improvement in EQE, reaching 15-30\% between 300 and $500 \mathrm{~nm}$ for dye-LDS layers. However the addition of the dye-LDS layer results in a slightly reduced EQE between 490 and $510 \mathrm{~nm}$. This is due to the overlap between the absorption and emission spectra which causes self-absorption (Ross et al., 2012; Ahmed et al., 2016a, 2016b). This reduction however is offset in the plasmonic layer which shows a significant increase of $25-40 \%$ between 300 and $500 \mathrm{~nm}$.

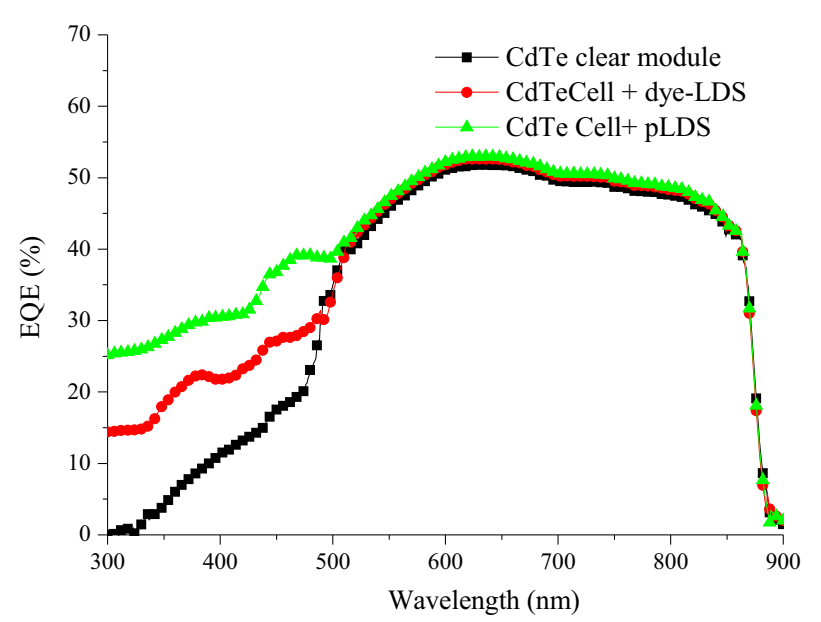

Fig. 9. EQE spectrum of CdTe mini-modules with no (i) LDS layer, (ii) with dye-LDS layer and (iii) with dye-pLDS composite layer.

The measured values of $\mathrm{J}_{\mathrm{sc}}$ and the measured EQE are related. The gain in short-circuit current density $\left(J_{s c}\right)$ from LDS layers is compared with that expected from the EQE measurements using the following equation (Ross et al., 2012);

$J_{S c}=q \int_{\lambda_{1}}^{\lambda_{2}} \varphi(\lambda) E Q E(\lambda) d \lambda$

where $q$ is the electron charge, $\varphi$ is the photon flux, $\lambda_{1}$ and $\lambda_{2}$ define the range of the spectrum for which $\mathrm{J}_{\mathrm{sc}}$ is to be calculated, and $\mathrm{EQE}$ is the measured external quantum efficiency. The $\mathrm{J}_{\mathrm{sc}}$ was calculated from AM1.5G ASTM standard and from Griven GR0262 solar simulator. The uncertainty of the $\mathrm{J}_{\mathrm{sc}}$ results is $\pm 5 \%$ due to the uncertainty of the EQE measurements. The relative increase was calculated for all CdTe devices for both light sources at the range $300-500 \mathrm{~nm}$ (where the dye is absorbing and the action of the LDS layer is more significant) and at 300-900 $\mathrm{nm}$ while J-V results, such as those presented in Fig. 9 and Table 2 were useful for confirming trends.

$\mathrm{J}_{\mathrm{sc}}$ calculated for the AM1.5G ASTM standard was found to be higher compared to Griven solar simulation which is due to the spectrum mismatch between lamps (Ahmed, 2015; Ahmed et al., 2016b). The results discussed here are for Griven solar simulation however, the results obtained from the AM1.5G calculations confirm the same trend.

Table 2(a) shows $\mathrm{J}_{\mathrm{sc}}$ calculated for CdTe mini-modules using a Griven GR0262 solar simulation and in (b) using AM1.5G ASTM for the dye-LDS layer with and without plasmonic interaction. An increase of $48.5 \%$ was calculated in the $\mathrm{J}_{\mathrm{sc}}$ at $300-500 \mathrm{~nm}$ for the dye-LDS layer compared to the CdTe mini module, while $97.9 \%$ was calculated for the pLDS composite layer. The enhancement in $\mathrm{J}_{\mathrm{sc}}$ due to the Ag NPs in the composite layer was found to be $33.3 \%$ compared to the LDS layer with only dye. At $300-900 \mathrm{~nm}$ the composite layer has shown an increase of $11.1 \%$ compared to $5.9 \%$ for the dye when they are both compared to the CdTe mini module.

Table 1

Measured J-V characteristic of CdTe mini-modules under Griven GR0262 + UV lamp solar simulator with dye-LDS layer and pLDS composite layer.

\begin{tabular}{|c|c|c|c|c|c|}
\hline & $\mathrm{J}_{\mathrm{sc}}\left(\mathrm{mA} / \mathrm{cm}^{2}\right)$ & $\mathrm{V}_{\mathrm{oc}}(\mathrm{V})$ & $\mathrm{FF}$ & $\eta(\%)$ & $\begin{array}{c}\Delta \mathrm{J}_{\mathrm{sc}} \% \\
\pm 0.03\end{array}$ \\
\hline CdTe & 11.5 & 10.9 & 0.52 & 5.3 & - \\
\hline Dye-LDS & 12.2 & 10.9 & 0.54 & 5.8 & 6.1 \\
\hline pLDS & 12.8 & 11.0 & 0.57 & 6.6 & 11.3 \\
\hline
\end{tabular}


Table 2

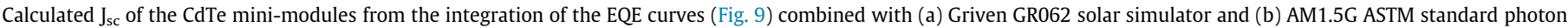
flux density with LDS layers.

\begin{tabular}{|c|c|c|c|c|}
\hline & $\begin{array}{l}\mathrm{J}_{\mathrm{sc}}\left(\mathrm{mA} / \mathrm{cm}^{2}\right) \\
300-500 \mathrm{~nm}\end{array}$ & $\begin{array}{l}\mathrm{J}_{\mathrm{sc}}\left(\mathrm{mA} / \mathrm{cm}^{2}\right) \\
300-900 \mathrm{~nm}\end{array}$ & $\begin{array}{l}\Delta \mathrm{J}_{\mathrm{sc}} \pm 0.05 \% \\
300-500 \mathrm{~nm}\end{array}$ & $\begin{array}{l}\Delta \mathrm{J}_{\mathrm{sc}} \pm 0.05 \% \\
300-900 \mathrm{~nm}\end{array}$ \\
\hline \multicolumn{5}{|c|}{ (a) $J_{s c}$ calculated from Griven GR0262 solar simulator } \\
\hline Clear & 1.0 & 11.7 & - & - \\
\hline Dye-LDS & 1.5 & 12.4 & 48.5 & 5.9 \\
\hline pLDS & 2.0 & 13.0 & 97.9 & 11.1 \\
\hline \multicolumn{5}{|c|}{ (b) $J_{s c}$ calculated from AM1.5G ASTM standard } \\
\hline Clear & 1.1 & 12.6 & - & - \\
\hline Dye-LDS & 1.7 & 13.4 & 54.5 & 6.3 \\
\hline pLDS & 2.2 & 14.1 & 100 & 11.9 \\
\hline
\end{tabular}

\section{Conclusion}

This work has studied the first reported plasmonic down shifting layers (pLDS) for CdTe solar cells. Composite layers were successfully fabricated by drop casting on glass substrates with varying Ag NPs concentration from 0 to $40 \mathrm{ppm}$ while fixing lumogen yellow dye concentration to an optimum concentration of $0.9 \mathrm{wt} \%$. This allowed the manipulation of spacing between the Ag NPs and the lumogen yellow dye particles. The presence of silver nanoparticles produced a plasmonic interaction that has significantly improved the absorption and emission of lumogen yellow dye molecules. A 90\% relative increase in the absorption and an $81 \%$ for the emission intensity was calculated for lumogen yellow dye at $\mathrm{Ag} \mathrm{NP}$ concentration of $20 \mathrm{ppm}$. These enhancements of the absorption and emission are promising for the enhancement of the performance of PV devices utilizing luminescent downshifting layers.

For the first time, plasmonic LDS has been shown to improve the $\mathrm{J}_{\mathrm{sc}}$ of CdTe mini-modules devices reaching up to $100 \%$ in the region 300-500 $\mathrm{nm}$ for pLDS composite LDS layer of lumogen yellow dye and Ag NPs, demonstrating the possible improvement due to the action of plasmonic interaction in the composite layers. Results from both $\mathrm{J}-\mathrm{V}$ and EQE measurements confirm this improvement. The presence of Ag NPs produced a surface plasmon response that has significantly improved the absorption and emission of lumogen yellow dye.

\section{Acknowledgments}

The authors would like to acknowledge funding from the Irish Higher Education Authority under the Strand 3 program (SEAR Project) and European Research Council (PEDAL Project Number 639760). The authors also acknowledge the FOCAS Institute for use of equipment and facilities at the Dublin Institute of Technology.

Authors gratefully acknowledge helpful assistance of Dr. Subhash Chandra. Also thanks goes to Dr. Donagh O'Mahony and Dr. Richard Winfield for allowing us to use their Bentham PVE300 facility at Tyndall National Institute as well for their assistance and helpful discussion.

\section{References}

Ahmed, 2015. Materials Characterization and Plasmonic Interaction in Enhanced Luminescent Down-Shifting Layers for Photovoltaic Devices PhD thesis. Dublin Institute of Technology, Ireland.

Ahmed, H., Doran, J., McCormack, S, 2016b. Increased short-circuit current density and external quantum efficiency of silicon and dye sensitised solar cells through plasmonic luminescent down-shifting layers. Sol. Energy 126, 146-155.

Ahmed, H., Kennedy, M., Doran, J., McCormack, S.J., Galindo, S., Voz, C., Puigdollers, J. 2012a. Lumogen violet dye as luminescent down-shifting layer for c-silicon solar cells. In: Proceedings of the 27th European Photovoltaic Solar Energy Conference and Exhibition, Frankfurt, Germany, pp. 311-313.
Ahmed, H., Kennedy, M., Doran, J., McCormack, S.J., Pirriera, M.D., Gutierrez-Tauste, D., Aubouy, L., 2012b. Characterization of luminescent down-shifting materials and applications for enhanced photovoltaic devices. In: Proceedings of the 8th Photovoltaic Science Application and Technology Conference and Exhibition. Northumbria University, UK, pp. 1-4.

Ahmed, H. McCormack, S., Doran, J., 2016a. External quantum efficiency improvement with luminescent downshifting layers: experimental and modelling. Int. J. Spectrosc., 1-7 8543475

Ahmed, H., Walshe, J., Kennedy, M., Confrey, T., Doran, J., McCormack, S., 2013. Enhancement in solar cells efficiency by luminescent down-shifting layers. Adv. Energy Res. 1, 117-126.

Bella, F., Griffini, G., Gerosa, M., Turri, S., Bongiovanni, R., 2015. Performance and stability improvements for dye-sensitized solar cells in the presence of luminescent coatings. J. Power Sources 283, 195-203.

Catchpole, K.R., Polman, A., 2008. Plasmonic solar cells. Opt. Express 16, 2179321799.

Chander, N., Sardana, S.K., Parashar, P.K., Khan, A.F., Chawla, S., Komarala, V.K., 2015. Improving the short-wavelength spectral response of silicon solar cells by spray deposition of YVO4: Eu3+ downshifting phosphor nanoparticles. IEEE J. Photovoltaics 5, 1373-1379.

Chandra, S., 2013. Approach to Plasmonic Luminescent Solar Concentration PhD thesis. Dublin Institute of Technology, Ireland.

Chandra, S., McCormack, S.J., Doran, J., Kennedy, M., Chatten, A.J., 2010. New concept for luminescent solar concentrator. In: Proceedings of the 25th European Photovoltaic Solar Energy Conference, Valencia, Spain, September, pp. 759-762.

Chandra, S., McCormack, S.J., Doran, J., Kennedy, M., Chatten, A.J., 2012. Enhanced quantum dot emission for luminescent solar concentrators using plasmonic interaction. J. Sol. Energy Mater. Sol. Cells 98, 385-390.

Chandra, S., McCormack, S.J., Kennedy, M., Doran, J., 2015. Quantum dot solar concentrator: optical transportation and doping concentration optimization. Sol. Energy 115, 552-561.

Di Lorenzo, M.L., Cocca, M., Avella, M., Gentile, G., Gutierrez, D., Della Pirriera, M., Torralba-Calleja, E., Kennedy, M., Ahmed, H., Doran, J., 2016. Down shifting in poly(vinyl alcohol) gels doped with terbium complex. J. Colloid Interface Sci. 477, 34-39.

Fort, E., Gŕesillon, S., 2008. Surface enhanced fluorescence. J. Phys. D Appl. Phys. 41, 013001-013031.

Gallagher, S.J., Rowan, B.C., Doran, J., Norton, B., 2007. Quantum dot solar concentrator: device optimisation using spectroscopic techniques. Sol. Energy $81,540-547$.

Ghosh, S.K., Pal, T., 2007. Interparticle coupling effect on the surface plasmon resonance of gold nanoparticles: from theory to applications. Chem. Rev. 107, 4797-4862.

Goetzberger, A., Greubel, W., 1977. Solar energy conversion with fluorescent collectors. Appl. Phys. 14, 123-139.

Griffini, G., Bella, F., Nisic, F., Dragonetti, C., Roberto, D., Levi, M., Bongiovanni, R., Turri, S., 2015. Multifunctional luminescent down-shifting fluoropolymer coatings: a straightforward strategy to improve the UV-light harvesting ability and long-term outdoor stability of organic dye-sensitized solar cells. Adv. Energy Mater. 5, 1401312.

Hovel, H.J., Hodgson, R.T., Woodall, J.M., 1979. The effect of fluorescent wavelength shifting on solar cell spectral response. Sol. Energy Mater. 2, 19-29.

Kennedy, M., Ahmed, H., Doran, J., Norton, B., Bosch- Jimenez, P., Della Pirriera, M., Torralba-Calleja, E., Tauste, D.G., Aubouy, L., Daren, S., Solomon-Tsvetkov, F., Galindo, S., Voz, C., Puigdollers, J., 2015. Large stokes shift downshifting Eu(III) films as efficiency enhancing UV blocking layers for dye sensitized solar cells. Phys. Status Solidi A 211, 203-210.

Kennedy, M., McCormack, S.J., Doran, J., Norton, B., 2009. Improving the optical efficiency and concentration of a single plate quantum dot solar concentrator using near infra-red emitting quantum dots. Sol. Energy 83, 978-981.

Klampaftis, E., Ross, D., McIntosh, K.R., Richards, B., 2009. Enhancing the performance of solar cell via luminescent down-shifting of the incident spectrum: a review. Sol. Energy Mater. Sol. Cells 93, 1182-1194.

Klampaftis, E., Ross, D., Seyrling, S., Tiwari, A.N., Richards, B.S., 2012. Increase in short-wavelength response of encapsulated CIGS devices by doping the encapsulation layer with luminescent material. Sol. Energy Mater. Sol. Cells $101,62-67$. 
Lakowicz, J.R., Shen, Y., D’Auria, S., Malicka, J., Fang, J., Gryczynski, Z., Gryczynski, I., 2002. Radiative decay engineering: effects of silver island films on fluorescence intensity, lifetimes, and resonance energy transfer. Anal. Biochem. 301, 261277.

Lakowicz, J.R., Geddes, C.D., Gryczynski, I., Malicka, J., Grynski, Z., Aslan, K., Lukomska, J., Matveeva, E., Zhang, J., Badugu, R., Huang, J., 2004. Advance in surface-enhanced fluorescence. J. Fluoresc. 14, 425-441.

Ledwith, D.M., Whelan, A.M., Kelly, J.M., 2007. A rapid, straight-forward method for controlling the morphology of stable silver nanoparticles. J. Mater. Chem. 17, 2459-2464.

Levitt, J.A., Weber, W.H., 1977. Materials for luminescent greenhouse solar collectors. Appl. Opt. 16, 2684-2689.

McIntosh, K.R., Lau, G., Cotsell, J.N., Hanton, K., Batzner, D.L., 2009. Increase in external quantum efficiency of encapsulated silicon solar cells from a luminescent down-shifting layer. Progr. Photovolt.: Res. Appl. 17, 191-197.

Meredith, G.H., Sheldon, T.B., Bruce, P.W., 2009. Photo-stability and performance of $\mathrm{CdSe} / \mathrm{ZnS}$ quantum dots in luminescent solar concentrators. Sol. Energy 83, 566-573.

Noguez, C., 2006. Surface plasmons on metal nanoparticles: the influence of shape and physical environment. J. Phys. Chem. C 111, 3806-3819.

Reisfeld, R., Eyal, M., Brusilovsky, D., 1988. Luminescence enhancement of rhodamine 6G in sol-gel films containing silver aggregates. Chem. Phys. Lett. $153,210-214$.
Reisfeld, R., 2010. New developments in luminescence for solar energy utilization. Opt. Mater. 32, 850-856.

Ross, D., Alonso-Álvarez, D., Klampaftis, E., Fritsche, J., Bauer, M., Debije, M.G. Fifield, R.M., Richards, B.S., 2014. The impact of luminescent down shifting on the performance of CdTe photovoltaics: impact of the module vintage. IEEE J. Photovoltaic 4, 457-464.

Ross, D., Klampaftis, E., Fritsche, J., Bauer, M., Richards, B.S., 2012. Increased shortcircuit current density of production line $\mathrm{CdTe}$ mini-module through luminescent down-shifting. Sol. Energy Mater. Sol. Cells 103, 11-16.

Rothemund, R., Kreuzer, S., Umundum, T., Meinhardt, G., Fromherz, T., Jantsch, W. 2011. External quantum efficiency analysis of si solar cells with II-VI nanocrystal luminescent down-shifting layers. Energy Procedia 10, 83-87.

Stranik, O., 2007. Plasmonic Enhancement of Fluorescence for Biomedical Diagnostics PhD thesis. Dublin City University, Ireland.

Stranik, O., McEvoy, H.M., McDonagh, C., MacCraith, B.D., 2005. Plasmonic enhancement of fluorescence for sensor applications. Sens. Actuators B 107 , $148-153$.

Van Sark, W.G., Meijerink, A., Schropp, R.E., Van Roosmalen, J.A., Lysen, E.H., 2005 Enhancing solar cell efficiency by using spectral converters. J. Sol. Energy Mater. Sol. Cells 87, 395-404.

Weber, W.H., Lambe, J., 1976. Luminescent collector for solar radiation. Appl. Opt 15, 2299-2300. 